\title{
Exploration of the Motivation Mode of Information Quality Education for Medical Students
}

\author{
Qinlan Zhang ${ }^{1 \mathrm{a}}$ Xueyuan $\mathrm{Yi}^{1{ }^{1{ }^{*}}}$ \\ ${ }^{1}$ Library of Chengdu Medical college, Chengdu 610500 \\ ${ }^{1} \mathrm{~b} *$ Corresponding Author \\ a1379028893@qq.com, b715419411@qq.com
}

\begin{abstract}
Information quality is the basic quality that should be equipped for medical students during the information era, and valid motivation of information quality education can mobilize the learning initiative of medical students. In the teaching process of information quality, it is applicable to improve the teaching effect of information quality education through the motivation of medical ethics, teaching atmosphere, teaching behaviors, learning objective, emotional spirits and so on, thereby helping medical students fast acquire and convert new knowledge in the modernized society where medicine develops at a high speed to become the informative innovative talents of the new era.
\end{abstract}

Keywords-Medical students; Information quality; Education motivation; Exploration

\section{INTRODUCTION}

Modernized society is the new era for the fast development of scientific and technological information, and the basic quality requested for contemporary college students is the capacity to fast acquire knowledge and lifelong learning capacity, and information quality has gradually become the basic conditions for people to obtain good development in information society. As the medical student of the information era, in the face of the fast development of modernized medicines and the transformation of medical mode, it not only requires solid professional knowledge and solid professional integrity, but also the capacity to fast acquire new medical knowledge and technologies, constantly optimize its own knowledge structure, and adapt to the demand of social service and the requirement of scientific research. Thus, in the face of the environment with many cognitive challenges brought by scientific and technological information, medical colleges must pay high attention to information quality education, validly use information quality course and library resources, explore targeted education motivation mode, and improve information quality education level. In the information quality education, it is requested to teach medical students learning methods, and enlighten them with reasons, help them constantly improve the quality capacity of medical colleges, and make them provide better service for the future medical sanitation career in the new era.

\section{FUNCTION OF EDUCATION MOTIVATION}

As an important concept in organizational behavior, motivation refers to a mental activity that can stimulate people's motive, make people have internal impetus and consciously make endeavors towards the scheduled objective, and motivation has been extensively applied in management, sociology and other fields. Through analyzing from the perspective of teaching management, the education of students is also a kind of management behavior, and should also similarly refer to motivation theory, and provide new thoughts to the education management of information quality disciplines. Contemporary college students have many characteristics, such as fast information receiving, new concepts, diversified demand motives, complicated psychological states and big emotional fluctuation, and through correct education motivation mode, it is requested to guide college students to cultivate the learning enthusiasm towards information quality in spirit, arouse their learning potential, cultivate correct cognitive habit and optimize their personality characteristics, especially when the contemporary doctor-patient relationship and medical environment are facing huge reform and challenge conditions, it is requested to make medical students form good learning habit and stable personality characteristics through information quality education motivation, which can be of great benefit to the future study and work

In order to get good education motivation effect, it is requested to adopt scientific and normalized motivation mode, break through the old education management thought, create good motivation environment, and fully mobilize students' enthusiasm to learn information quality course. Teachers should implement motivations and shouldn't merely have the thought without taking any actions and should avoid teaching motivation from being turned into an armchair strategist [1]. In the motivation process, it is requested to pay attention to the combination of various motivation modes in use, and single motivation mode can make the effect weaken gradually, and make students constantly generate new struggling target. Education motivation should implement differential treatment, and students in different grades, discipline background and learning status have different psychological states, so when applying motivation mode, it is requested to teach students in accordance of their aptitude and make dynamic adjustment. 


\section{PROBLEMS IN EDUCATION MOTIVATION}

Imperfect motivation mechanism; although various colleges are constantly formulating motivation mechanism for students, and released relevant regulations and rules, hoping to promote college students to study actively and study hard to become a useful person. However, most motivation mechanisms still take the academic performance of students as the measurement standard and neglect the subjectivity and personalized development of students. Although colleges encourage college students to develop morally, intellectually, physically and aesthetically, most motivation policies can only cover excellent students, and it is hard for common college students to enjoy the impetus brought by motivation and many motivation measures become formalistic in the specific implementation process.

Old motivation mode; the life experience, knowledge structure, and character trait of each college student are verified, so they can be different in personal morality, learning capacity, communication capacity and other aspects. Thus, the motivation mode for education workers shouldn't merely stay at the past traditional motivation, and it is requested to adopt different motivation modes as per the time, place and individual. Currently, most college education workers fail to comprehensively consider students' demand, and solely adopt some relatively traditional motivation methods. It is mainly the material motivations of scholarship, award and the certificate of merit, neglect students' spiritual and emotional demands, which will cause the dislocation of motivation and demand. Meanwhile, the motivation mode adopted in many colleges is focused on positive motivation, and few colleges will implement setback motivation for college students, and when using such negative motivation mode to help students face setbacks, it is aimed to educate them to calmly face problems and find out the reasons of failure, and then cultivate college students' willingness to solve tough problems. Thus, if colleges rely too much on the motivation mode of award and motivation, the promotion effect of negative motivation will be neglected.

Relatively bad motivation atmosphere; motivation atmosphere is an important factor influencing the motivation effect of college students, and the influence of atmosphere on college students is imperceptible. But due to the horizontal differentiations in the construction of colleges, many colleges remain to be improved in campus culture and infrastructure construction. However, the school spirit, study style and teaching style are way too serious in some colleges, and the relationship between teachers and students is indifferent and they lack in emotional exchange. All of these factors have caused the loss of motivation atmosphere, and seriously influenced the effect of education motivation in colleges.

\section{MOTIVATION MODE FOR INFORMATION QUALITY} EDUCATION

In the information quality education, motivation mechanism is applied to mobilize students' initiative, creativity and enthusiasm, and the application of scientific and reasonable education motivation can fill up the defects in course teaching management, and fully combine information quality course and the professional knowledge of medicine, the learning characteristics of medical students, psychological thoughts, etc., cultivate students' information quality thought, and gradually improve the quality of information quality education.

The motivation of medical ethics; the basic principle for medical ethics in our country is "healing the wounded and rescuing the dying, implementing the prevention and treatment of diseases as well as socialist medical humanitarian, and wholeheartedly serving for people's health." The compliance of medical ethics can help regulate the interpersonal relationship of medical workers in medical practice activities, and medical ethics are the most basic starting point and guidance criterion for medical workers and social relationship, and also the ruler measuring the level of professional ethics for medical workers. Make medical ethics run through information quality education, and let medical students correctly treat and master the relationship between discipline knowledge and the future medical professional career and understand the essential task of socialist medical sanitation career and the requirements for medical workers. In the teaching process of information quality, use medical ethics to guide medical students to fully recognize the unification of medical scientificity and morality, and make medical students realize that the requirement of modernized medical career is to fast acquire cutting-edge medical knowledge, seize correct learning approach, and possess medical information quality, and it is also an important approach for medical workers to "wholeheartedly provide service to people's health", help them better establish the rigor and inquiring spirits for medicine, and conscientiously use medical ethics to strictly request themselves to hold serious learning attitude towards medical information quality course.

The motivation of teaching atmosphere; contemporary college students have stronger awareness of freedom and personality, and deep inside their hearts, they are opposed to the domineering "management" of teachers or the elder, so depressive and stiff teaching atmosphere will easily cause the generation of students' reverse psychology and learningweariness, so the creation of harmonious teaching atmosphere and interpersonal environment can improve teaching effect. Teaching atmosphere can influence the mutual teaching and learning effect between teachers and students, and in a good teaching atmosphere, teachers and students trust each other, care for each other, mutually respect, and act in harmony, which can make the teaching and learning quite easy and pleasant, and under such atmosphere, it is certainly full of joy to learn information quality course, and students' enthusiasm and creativity can also be fully played. The creation of a good teaching atmosphere can reasonably use honor motivation, and model motivation. Honor motivation is the spiritual and material award for students' academic performance and 
learning behaviors. Honor is the high-level demand of people, and when a student' sense of honor is satisfied, he will be passionate in course learning, feel the learning value and the enrichment of his own knowledge reserves, and gain big satisfaction in spirit, so it will exert a good motivation effect. On the other hand, the model force in modernized society is still undeniable; a model is the best demonstration, and the soundless guidance. Thus, teachers of information quality course should be good at finding learning models, establishing models, and applying models, create demonstration effect through typical learning case, and make students dig out their own aspects to be promoted and improved from these models, and stimulate students to study hard to improve their learning capacity and learning enthusiasm.

The motivation of teachers' behaviors; the motivation of teachers' behaviors refers to exerting the due function of learning guide and teaching management function of teachers undertaking information quality course through adopting correct teaching mode and method, and for students, it is a kind of intangible motivation. Teachers should show their professional knowledge and good ethics and styles as teachers, and let students generate convenience and affiliation, and they should use their own good teaching behaviors to stimulate students' interest in information quality course [2]. On one hand, teachers undertaking information quality course should pay attention to the constant upgrading of professional knowledge about the course, reflect the requirements of the constantly developed society for the information quality of medical students, and show students their own professional information quality knowledge reserves, and make medical students feel the importance and practicability of this course in the course teaching full of knowledge and modernity. On the other hand, teachers of information quality course should also establish a good teacher's prestige among students, expect for the teaching of professional knowledge, and should use their own good teaching behavior to win the cognition of students, maintain the course progress and teaching process, and make the course plan complete on schedule.

The motivation of learning objective; valid objective motivation can stimulate mental motive, and constantly increase behavior enthusiasm, and can stimulate students' internal impetus for making progress in the constant pursuit process of learning objective. Set suitable learning objective, and then through the guiding function of objective motivation, promote medical students to study hard the information quality course. In the information quality education, it is requested to fully set learning objective specific to the differentiation and demand of different student groups, fully consider the correctness, adaptability, hierarchy, challenge, reality, deadline, etc. of objectives, make medical students achieve their aims and keep constantly learning enthusiasm to the largest extent. The objective motivation of information quality education can cultivate medical students to keep the faith in the objective and promote them to have clear and specific actions in each learning period, so as to reach to the effect of learning motivation. Besides, the form for the motivation of learning objective should also be flexible and verified and focus on the feedback of motivation process; the learning objective set thereby cannot be kept unchanged for a long time, and it is also requested to timely correct objective and adjust behaviors deviating from the objective.

Spiritual motivation; many industrial fields of the contemporary society promote humanized concept and pay more and more attention to the method of spiritual motivation. It is also applicable to refer to spiritual motivation mode in information quality education, combine flexible spiritual motivation and rigid teaching system, and let medical students play learning enthusiasm, initiative and creativity in rules and regulations, and keep the fresh vigor of information quality teaching. Meanwhile, spiritual motivation should also be combined with other motivation means and reach to a kind of dynamic balance. Spiritual motivation should also reinforce the affective communication with students in the information quality teaching process, validly seize college students' emotional changing rules, respect their own individualized development, understand their spiritual demand, care for their growth, establish a healthy and positive teacher-student relationship, use emotions to stimulate students' learning enthusiasm, and use spiritual force to promote students to keep their learning impetus [3]. Of course, spiritual motivation also has big relation with the quality and capacity of the implementing teachers, and not all teachers of information quality education course can fully master the art of motivation and humanity, so in order to use spiritual motivation method to obtain better effect, it is also requested to reinforce the quality and capacity cultivation of teachers, and widely study excellent experience.

\section{CONCLUSION}

Medical information quality education is an important course to educate students to improve their learning capacity and make them master the dynamic information about medicine. In the new era, medical students are not only the representatives of scientific rationality, but also have humanistic feelings and sensibility and should become medical talents who pay equal attention to both professional skills and comprehensive quality. Meanwhile, contemporary college students are no longer pure learning machine, instead, attentions are gradually paid to the spiritual pleasure and satisfaction brought by learning. Thus, information quality course teachers should correctly use motivation methods as per the learning demand, motivation, emotions and other psychology activity rules of medical students, scientifically master the motivation process, focus on the function of education motivation, constantly explore and innovate the motivation mode of information quality education, and improve the teaching effect of information quality course. 


\section{ACKNOWLEDGMENT}

About the Author: Qinlan Zhang (1990-), master of management, and the Assistant Librarian for the Library of Chengdu Medical College, and the research direction is library science.

Corresponding Author: Xueyuan Yi (1972-), research assistant and the research direction are library management.

Contact Information: Library of Chengdu Medical College located at No. 783, Xindu Avenue, Xindu District, Chengdu City, Sichuan Province

1379028893@qq.com18428301825

\section{REFERENCES}

[1] Xianwei Liu. Brief Discussion about the Application of Education Motivation in the Education Management of College Postgraduates [J]. Business Administrator, 2015, (08): 389.

[2] Xuefeng Wu, Dongkui Yan and Hao Liu. Discussion about How to Build the Education Motivation Mechanism for College Students [J] Science and Technology, 2015, 25(01): 289.

[3] Tian Liu. Construction of Ideological and Political Education Motivation Mechanism for College Students [J]. Heilongjiang Science, 2017, 8 (05): 120-121.

[4] Chuting Zhou. Analysis on the Ideological and Political Education Motivation Mechanism for College Students during the New Period [J]. Contemporary Education Practice and Teaching Research, 2017, (01): 67-68.

[5] Shuman Feng. Research about Ideological and Political Education Motivation Mechanism under Positive Psychology Perspective [J]. Comparative Study of Cultural Innovation, 2017, 1 (23): 92-94.

[6] Zirui Tian. Application of Emotional Motivation in the Education Management of College Students [J]. Estate and Science Tribune, 2017, 16 (02): 274-275 